\title{
Energy performance of an industrial superheated steam heat pump flash dryer for drying of bio-fuel
}

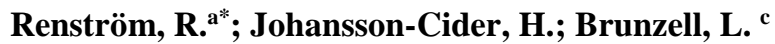 \\ ${ }^{a}$ Karlstad University, Environmental and Energy Systems, 65188 Karlstad, Sweden, \\ Tel +46547001000
}

*E-mail of the corresponding author: roger.renstrom@kau.se

\begin{abstract}
Drying is an energy demanding industrial process and methods for reducing the energy consumption of drying is of interest to industry as well as society. This article presents the drying system of a biofuel factory. Steam is used as the refrigerant. Superheated steam is used as drying gas in a flash dryer with 28.8 tons/h dewatering capacity. The system includes an energy recovering water heat pump that receives its heat from the excess drying steam and heats the dryer. The SMER of the drying process ranges between 3 and 4 and the COP of the heat pump process ranges between 4 and 5.5 during one production season of peat drying. Variations in performance can be explained by variations in inlet moisture content and production rate. The example of this drying system shows the feasibility of drying in superheated steam, heat pump drying and water as refrigerant in high-temperature heat pumps.
\end{abstract}

Keywords: steam drying; heat pump process; peat; sawdust; industrial operation 


\section{Introduction}

Methods for reducing the energy consumption of drying processes are of interest to industry as well as society. There is also a desire to replace fossil fuels with renewable fuels, such as fuel pellets or briquettes made from biomass. Compact biomass in the form of fuel pellets or briquettes has a higher heating value, lower moisture content and higher density than unprocessed biofuel; their properties are also more uniform. Pelletizing or briquetting thus improves transport properties as well as storage and combustion properties [1].

Wet biomass must be dried before briquetting and pelletizing. Various dryer designs can be chosen, depending on the properties of the material being dried and on available sources of energy [2]. Packed moving bed dryers can achieve the desired moisture content of 5-25\% at drying temperatures of $80-150^{\circ} \mathrm{C}$. They are relatively cheap, but require a larger installation area than other dryers. Rotary dryers are common for drying woodchips and sawdust. They operate reliably and enable heat recovery from the exhaust drying medium, which increases the energy efficiency of the system. Pneumatic dryers, also known as flash dryers, are compact and suitable for drying particles or granules [3]. In a flash dryer the particles are mixed with a high temperature drying gas, often air or flue gas, and transported by the drying gas at a high velocity. High flow velocity mixes well and gives high heat and mass transfer rates. The technology is, however, associated with high energy consumption. Typical energy consumption for a flash dryer is $4500-9000 \mathrm{~kJ} / \mathrm{kg}$ of water [2], but energy efficiency can be improved by heat recovery of the exhaust drying medium [3]. In a flash dryer, steam can be used as drying gas. Steam has many advantages over air and flue gas. The energy advantage of steam as drying gas is that it simplifies heat recovery by enabling dryer integration, which is the factor that determines the energy efficiency of a steam dryer [4]. By recovering energy in a superheated steam drying process, more than $90 \%$ of energy needs can be reduced [5]. As an example, a superheated steam flash dryer at Rockhammar mill, Sweden, uses 0.4-0.7 GJ per ton pulp whereas the same flash dryer with air as drying gas requires 3.0-3.5 GJ per ton pulp, a reduction by 75-90 \% [6]. The environmental advantage of steam drying is that the dryer does not result in air pollution, since drying gas is not released into the atmosphere. The excess steam condensate will, on the other hand, need wastewater treatment as it can contain terpenes, fatty acids, formaldehyde and other types of contamination, depending on type of biomass and drying conditions. These organic compounds are released from the biomass as it is heated [7] [8] [9] [10] [4]. A further benefit of steam drying is that since there is no oxygen present in the dryer no oxidation can occur, this in turn leads to a minimal risk of ignition during operation [6].

Heat pump drying is a way of reducing energy consumption even further. It also brings additional benefits such as improved process control, which in its turn is beneficial for the quality of many dried products, such as foodstuffs. Drying of foodstuffs and timber are the two fields in which heat pump drying has so far reached the market [11]. The technology of 
heat pump drying has been known for decades, but it is still under-exploited. Heat pump dryers are claimed to be complex systems: a change in one component brings changes to other components as well [11] [12].

This article describes an example of large-scale industrial heat pump drying of biofuel. In the heat pump drying system, steam is used both as drying gas in a flash dryer, and as refrigerant in a vapor compression heat pump cycle. It was designed by GEA Exergy and built by MoDo Chemetics in 1989 for peat drying, but is today also used for sawdust drying. Production data differs between sawdust and peat drying. To enable comparison with dimensioning data this article focuses on peat drying. The system layout is presented, along with its energy performance for one production season of peat drying. Variations in energy performance, deviation from dimensioning data, and experiences from operation are considered. Implications of this drying system for the design of future biomass dryers are finally discussed.

\section{Materials and Methods}

The dryer is part of a stand-alone biofuel factory with two identical lines for drying, each one with a design capacity of dewatering 28 tons/h. The plan for $2016-2017$ is to produce 83,000 tons of wood fuel pellets and 25,000 tons of peat fuel briquettes. This drying system uses steam both as drying gas in a flash dryer, and as refrigerant in a vapor compression heat pump cycle. These two steam cycles are never mixed. In this article, drying steam denotes steam in the drying cycle and refrigerant denotes the water vapor in the vapor compression cycle.

\subsection{Dryer}

A flash dryer is used in which small particles of peat or sawdust are mixed with drying steam and transported through the dryer. Two fans in series circulate the drying steam. The dryer consists of five vertical shell-and-tube heat exchangers, each 20 meter high, as can be seen in Figure 1.

Refrigerant condenses on the shell side of the heat exchangers, transferring its latent heat to the drying steam. Drying steam and wet biomass flow inside the tubes. Each shell holds 73 or 97 tubes. The number of tubes increases with the direction of the drying process. Wear has caused some tubes to break, and to prevent leakage from the shell side to the tube side, these tubes have been welded shut, which reduces the heat transfer area of the dryer by $12 \%$ in Line 1 and $8 \%$ in Line 2 compared with design. The residence time of the biomass in the flash dryer is approximately 20 seconds. 


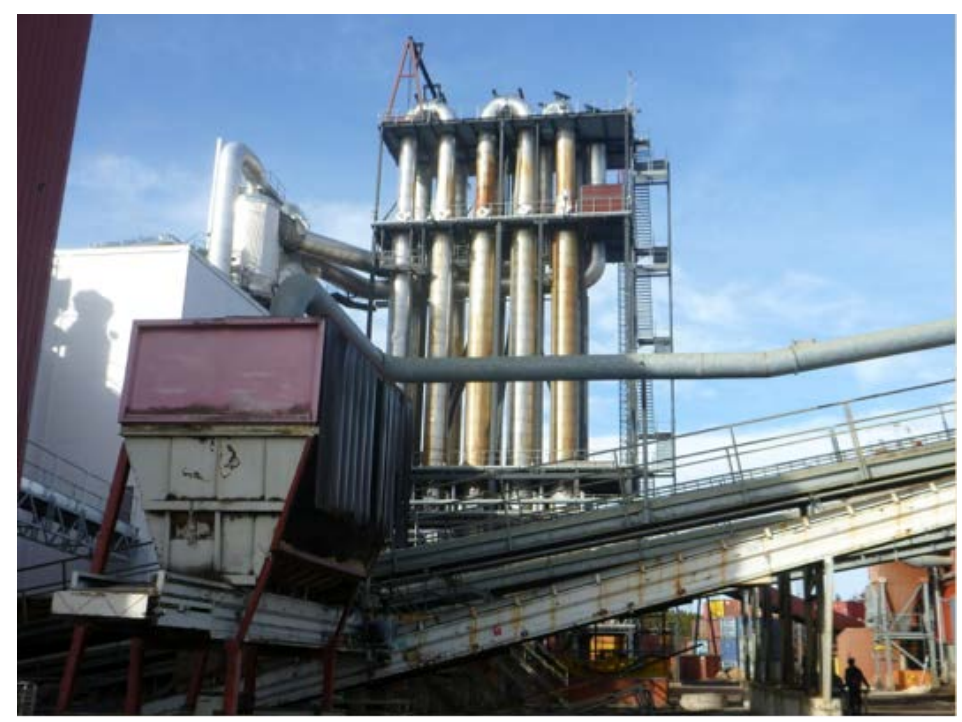

Fig. 1 The five 20m high heat tube shells.

\subsection{Biomass}

Inlet moisture content of the grinded peat varies between $55 \%$ and $65 \%$ during a season. Short-term variations in moisture content of incoming raw material can cause fluctuations in the system and need to be avoided, whereas the long-term variations are well known. Lower moisture content is found at the end of the summer and the moisture content then increases during winter due to outdoor storage.

The first step before drying is preheating. Preheating is done at atmospheric pressure with an excess flow of flash steam and venting steam that is in contact with the biomass. Since steam condenses on the biomass in the preheater, it is impossible to determine the temperature and moisture content of the biomass accurately as it enters the flash dryer. The biomass enters the dryer through a mixing chamber where it is mixed with the drying steam; it is then transported through the five heat exchangers of the flash dryer by the flow of drying steam. Dry biomass is separated from the drying steam in a cyclone. Before leaving the system, the material goes into the flash tank where the pressure is reduced to atmospheric pressure. The moisture content at the outlet is $8-10 \%$.

\subsection{Refrigerant}

The refrigerant is water and works in a vapor compression heat pump process. After the compressor, the refrigerant pressure is $1.0-1.4 \mathrm{MPa}$ and the temperature is $220-240{ }^{\circ} \mathrm{C}$. At this state the refrigerant enters the flash dryer, where it is cooled down to its saturation temperature, condensates and leaves the dryer as saturated liquid. Its heat is transferred to the 
drying steam and enables the water in the biomass to evaporate. In the superheater/subcooler, the liquid refrigerant is subcooled, thereby superheating the drying steam. The expansion valve is included in the steam converter, where the refrigerant pressure is dropped to 0.32 MPa. Liquid refrigerant receives heat from the excess drying steam and vaporizes. It then enters the four-stage turbo compressor as saturated steam at $0.32 \mathrm{MPa}$. The refrigerant mass flow rate is approximately $8 \mathrm{~kg} / \mathrm{s}$ and the compressor has a maximum power consumption of 4.0 MW. If required, more refrigerant can be added to the system from a supply water tank included in the steam converter.

\subsection{Performance parameters}

The Specific Moisture Evaporation Rate (SMER) is defined as

$$
S M E R=\frac{\text { amount of } \text { water evaporated }}{\text { energy input to dryer }}=\frac{m_{\text {excess steam }}}{w_{\text {compressor }}+w_{\text {fan }}}, \mathrm{kg} / \mathrm{kWh}
$$

The reciprocal of SMER is the Specific Energy Consumption (SEC);

$$
S E C=\frac{\text { energy input to the dryer }}{\text { amount of water evaportated }}
$$

In Equations 1 and 2, the amount of water evaporated is the same as the amount of excess steam condensate. The total energy supplied to the dryer is the electrical energy supplied to the compressor and the fans.

The COP, the coefficient of performance, determines the effectiveness of a heat pump process:

$$
\text { COP }=\frac{\text { Desired output (heat) }}{\text { Required input }(\text { work })}=\frac{Q_{\text {dryer }}}{w_{\text {compressor }}}
$$

In Equation 3 the desired output is the heat released from the refrigerant as it condenses in the dryer and the required input is the electrical power to the compressor. The desired output (Qdryer), is calculated using Equation 4.

$$
Q_{\text {dryer }}=\left(h_{\text {in }}-h_{\text {sat }}+h_{f g}\right) \cdot m_{\text {refridgerant. }}, k W
$$

\section{Results}

Results are presented for the averages of the selected performance indicators and their variations during the production season. Dimensioning data of the factory are included for comparison. The average values of the performance parameters are reported in Table 1, in which the dimensioning data and operational data during 2014-2015 are compared. The dimensioning data represent the maximum capacity of the drying system under ideal conditions. As can be seen in Table 1, it was not operated at maximum capacity during the 
production season of 2014-2015. The dewatering rate was approximately $76 \%$ of the dimensioning value. It should be noted that the total power consumption was larger in the operational data, despite a lower production rate. Contrary to what could be expected based on production rate and power consumption, the value of COP is higher in operational data than in dimensioning data.

Table 1. Average values of performance parameters along with dimensioning data.

\begin{tabular}{lrrr}
\hline & \multicolumn{2}{c}{$\begin{array}{c}\text { Dimensioning } \\
\text { data }\end{array}$} & \multicolumn{2}{c}{ Operational data } \\
& 22.2 & 13.8 & 15.6 \\
\hline Production rate $\{$ tons/h\} & 27.8 & 20.6 & 21.5 \\
Moisture evaporation rate $(\mathrm{MER})\{$ tons/h\} & 60.0 & 63.6 & 61.9 \\
Inlet moisture content $(\mathrm{MC})\{\%\}$ & 5390 & 5680 & 5550 \\
Total power consumption $\{\mathrm{kW}\}$ & & & \\
& 4 & 4.32 & 4.64 \\
Coefficient of performance (COP) & 210 & 276 & 260 \\
Specific energy consumption (SEC) $\{\mathrm{kWh} / \mathrm{ton}\}$ & 5.16 & 3.63 & 3.87 \\
Specific moisture evaporation rate (SMER) $\{\mathrm{kg} / \mathrm{kWh}\}$ & & &
\end{tabular}

\section{Discussion}

As reported in Table 2, the operational data shows lower values of production rate and moisture evaporation rate than does the dimensioning data. This result is expected; the factory is not operated at its full production capacity. More interesting results from Table 2 is that both the total power consumption and the value of COP is higher during operation than in the dimensioning data. The lower refrigerant condensation temperature that is required to achieve the desired drying rate can explain the higher value of COP. As the temperature difference between condenser and evaporator of the heat pump cycle decreases, COP increases. This also explains the variations in COP that are seen during the season. In order to achieve a higher production rate, the discharge pressure of the compressor is raised, thereby raising the condensing temperature and decreasing COP. The larger value of total power consumption can perhaps be due to deterioration of the components after many years of use, and the decrease in heat transfer are that is seen due to wear. SMER ranges between 3 and 4 with averages of 3.63 and 3.87. As can be seen in Figure 8 and Figure 10, the maximum values of SMER and COP are not coinciding. This shows the importance of specifying both dryer performance, such as SMER or SEC, and heat pump performance, 
COP, when reporting the performance of a heat pump dryer. The differences in performance between Line 1 and Line 2 are likely to be due to larger heat transfer area in Line 2.

The factory has supplied all data that are used in calculations of performance parameters. Data on power consumption and production rate are very important for their economic monitoring and should be considered as highly reliable. The only measurement that can be doubted on its quality is the refrigerant flow rate, which is used in the calculation of COP. Its average value is however correct and the average values of COP presented in this article can thereby be considered as reliable.

Heat pump performance and temperature range largely depends on the refrigerant used. Refrigerants today often have negative side effects on environment and human health and represent a fire hazard. Water has none of the negative side effects that are seen in other refrigerants. Using water as refrigerant enables heat pumps to reach higher temperatures; the temperatures needed for many industrial purposes. Water refrigerant heat pumps can thus find application both in upgrading waste heat into useful heat or steam, and in drying systems requiring a higher drying temperature than what can be reached with traditional refrigerants. The compressor is reported by scientific literature to be a challenging component in the water refrigerant heat pump, but in this drying system there have been no compressor problems. In high-temperature heat pump systems, water is the ideal refrigerant.

This heat pump dryer is a complex drying system. The drying cycle and the heat pump cycle are linked together both in the flash dryer and in the steam converter. Fluctuations in inlet moisture content of raw material will cause fluctuations in the amount of excess steam available for vaporizing the refrigerant. Finding and maintaining the energy balances at the right pressures represents a difficulty when operating the system as fluctuations causes variations in outlet moisture content and product quality. But this unique system has proven successful by running continuously with only small modifications from 1989 until today (2017).

\section{Conclusion}

Knowledge from operation of this dryer is valuable for designing efficient new drying systems. It proves both that complexity does not have to be a problem for heat pump dryers and that water is an excellent refrigerant in high temperature heat pumps. 


\section{References}

[1] Ståhl, M., Wood fuel pellets : sawdust drying in the energy system. Karlstad University studies: 2005:47. 2005: Karlstad : Division for Engineering Sciences, Physics and Mathematics, Department of Environmental and Energy Systems, Karlstads universitet, 2005.

[2] Mujumdar, A.S., Handbook of Industrial Drying. Vol. 2. 1995: Marcel Dekker Inc.

[3] Pang, S. and A.S. Mujumdar, Drying of Woody Biomass for Bioenergy: Drying Technologies and Optimization for an Integrated Bioenergy Plant. Drying Technology, 2010. 28(5): p. 690-701.

[4] Wimmerstedt, R., Steam Drying — History and Future. Drying Technology, 1995. 13(57): p. 1059-1076.

[5] Sloth Jensen, A., Drying in superheated steam under pressure, in Fifth Nordic Drying Conference. 2011: Helsinki, Finland.

[6] Romdhana, H., C. Bonazzi, and M. Esteban-Decloux, Superheated Steam Drying: An Overview of Pilot and Industrial Dryers with a Focus on Energy Efficiency. Drying Technology, 2015. 33(10): p. 1255-1274.

[7] Banerjee, S., Mechanisms of terpene release during sawdust and flake drying. Holzforschung, 2000. 55(4): p. 4.

[8] Björk, H. and A. Rasmuson, Formation of organic compounds in superheated steam drying of bark chips. Fuel, 1996. 75(1): p. 81-84.

[9] Spets, J.P. and P. Ahtila, Reduction of organic emissions by using a multistage drying system for wood-based biomasses. Drying Technology, 2004. 22(3): p. 541-561.

[10] Granstrom, K., Emissions of monoterpenes and VOCs during drying of sawdust in a spouted bed. Forest Products Journal, 2003. 53(10): p. 48-55.

[11] Chus, K.J., et al., Heat Pump Drying: Recent Development and Future Trends. Drying Technology, 2002. 20(8): p. 1579-1610.

[12] Minea, V., Heat-Pump-Assisted Drying: Recent Technological Advances and R\&D Needs. Drying Technology, 2013. 31(10): p. 1177-1189. 